\title{
Preparation and characterization of activated carbon $\&$ amorphous silica from rice husk
}

\author{
M. T. Rhaman ${ }^{1}$, M. A. Haque ${ }^{1}$, M. A. Rouf ${ }^{2 *}$, M. A. B. Siddique ${ }^{2}$ and M. S. Islam ${ }^{2 *}$ \\ ${ }^{1}$ Organic Research Laboratory, Department of Chemistry, Jagannath University, Dhaka, Bangladesh. \\ ${ }^{2}$ Institue of Fuel Research \& Development, Bangladesh Council of Scientific \& Industrial Research, Dr. Kudrat-e-Khuda Road, \\ Dhanmondi, Dhaka-1205, Bangladesh.
}

\begin{abstract}
Activated carbon (AC) was prepared by the conventional carbonization and $\mathrm{KOH}$ activation and amorphous silica was extracted by alkali extraction followed by acid precipitation from rice husk on a laboratory scale. The performance of the produced activated carbon and amorphous silica were examined using I2 value measurement, methylene blue (MB) adsorption test, pH measurement, FTIR and SEM-EDX analysis. The optimum temperature for production of $\mathrm{AC}$ was obtained at $700 \mathrm{0C}$. The $\mathrm{AC}$ by alkali extraction method was show higher activity than $\mathrm{KOH}$ activation. The maximum $\mathrm{I} 2$ value, $\mathrm{MB}$ adsorption value \& $\mathrm{pH}$ value shows at $700 \mathrm{0C}$ followed by alkali extraction with $15 \% \mathrm{NaOH}$, which were $510.82 \mathrm{mg} / \mathrm{g}, 61.1 \mathrm{mg} / \mathrm{g}$ and 7.32 respectively. The FTIR analysis shows presence of Si-O-Si bond with a strong peak at $1078.28 \mathrm{~cm}-1$. The SEM image of silica sample shows that the most of organic component is burnt out during combustion.
\end{abstract}

Keywords: Activated carbon; KOH activation; Carbonization; Amorphous silica; Alkali extraction

\section{Introduction}

Rice husk (RH) is an agricultural waste abundantly available in rice-producing countries. They are the natural sheaths that form on rice grains during their growth. These husk have no commercial interest as they are removed during refining of rice (Real et al., 1996). Increase of environmental awareness has led to a growing interest in researching ways of an effective utilization of rice by-product, from which rice husk is particularly valuable due to its high content of amorphous silica (Shigetaka et al., 2005; Yamaguchi et al., 2006). The RH contains $80 \%$ organic volatile matters and remaining is silica.

The chemical composition of the $\mathrm{RH}$ ash varies from sample to sample which may be due to the different geographical conditions, type of paddy, climatic conditions and type of fertilizer used (Bining and Jenkins, 1992; Houston, 1972 ). It was found that RH char contains amorphous silica in addition to amorphous carbon as the main constituents (Yamaguchi et al., 2006). Many authors have concluded that rice husk is an excellent source of high grade amorphous silica (Chen and Chang, 1991; Ghosh et al., 1991; Nandi et al., 1991). This portion of the silica cannot be dissolved in alkali and can withstand very high temperatures (Patel et al., 1991).
Production of activated carbon from rice husk has also have peoples interests. Active carbon has good adsorption property, can be produced from a variety of raw materials, such as packing papers, plastic bottles, by-products of the timber industry (e.g. sawdust), straw, rice husk, seeds or fruit shell can be mentioned. Interest is growing on agricultural waste for the production of activated carbon. Production of activated carbon from rice husk is achieved through activation with chemical or physical means (Alvarez et al., 2015 ; Van and Thi, 2014). Chemical impregnation with $\mathrm{KOH}, \mathrm{NaOH}, \mathrm{ZnCl}_{2}$ or $\mathrm{H}_{3} \mathrm{PO}_{4}$ of pyrolysed rice husk followed by activation at $650-850^{\circ} \mathrm{C}$ results in activated carbons with extremely high surface areas (750-3014m²/g) (Guo et al., 2002; Kalderis et al., 2008). The chemicals used to remove the silica so as to increase the pore in the rice husk. The RH ash is high in silica content and the loose wet structure of rice husk is destroyed after rice husk combustion in high temperature. While silicon dioxide is extracted from the $\mathrm{RH}$ ash, the carbon content is increased greatly in the residue, which is more economical for active carbon preparation in order to realize the farthest value of the agricultural waste. 
The objective of the research was to production of AC and amorphous silica from rice husk and characterize for efficient utilization of waste materials. The properties of amorphous silica and activated carbon from these locally available rice husks from Bangladesh are comparable to some other studies (Liu et al., 2012; Liu et al., 2011).

\section{Materials and methods}

\section{Sample Collection}

The Rice husk has been collected from Gazipur in Bangladesh. The collected rice husk has 8-10 mm length, $2.0-2.5 \mathrm{~mm}$ width and $0.1-0.15 \mathrm{~mm}$ of thick. The chemical properties of the collected rice husk sample were determined by proximate and ultimate analyses. Proximate analysis has been done according to the American Society for Testing Materials (ASTM, 1994).

\section{Chemicals}

Potassium Hydroxide (Merck KGaA, Germany), Hydrochloric Acid (Caledon, TMG), Sodium Hydroxide (Merck KGaA, Germany), Sodium Thiosulfate (BDH, England), Iodine (Merck KGaA, Germany), Potassium Iodide (Fair Lawn, USA), Potassium Iodate (BDH, England), Starch (Sigma Aldrich, GmbH), Sodium Carbonate (Merck KGaA, Germany), Methylene Blue (LOBA Chemical, India) and Sodium Chloride (Merck KGaA, Germany). All chemicals except solvents were used as received. Solvents were dried by standard methods and distilled under an inert atmosphere.

\section{Preparation of raw materials}

The rice husk was washed thoroughly with distilled water to remove adhering soil and clay and then dried in air at $105{ }^{\circ} \mathrm{C}$ in an oven for 24 hours. The rice husk was milled and then passed through different sieves. The particle size between 500-250 $\mu \mathrm{m}$ was selected for further pretreatment.

\section{Reactors for pyrolysis}

Activated carbon was produced from the above starting materials by carbonization in a horizontal tube furnace. The reactor is made of $1.5 \mathrm{~m}$ long steel tube with $100 \mathrm{~mm}$ internal diameter. The temperature is controlled by a proportional integral derivative (PID) temperature control and also a thermocouple placed at the center. To maintain the inert atmosphere purified nitrogen gas $(99.99 \%)$ were used and flow rate was control by using flow meter. Preparation of Activated Carbon (AC) by chemical activation and preparation of Amorphous Silica by alkali $(\mathrm{NaOH})$ extraction method shows in Fig. 1 and Fig. 2 respectively.

\section{Characterization of activated carbon}

Iodine value

To gain the knowledge of porous structure of activated carbon, iodine adsorption from liquid phase was adopted by other researchers (Martin et al., 2003) in the characterization of sludge-based activated carbons. The adsorption of aqueous $\mathrm{I}_{2}$ is considered a simple and quick test for evaluating the surface area of activated carbons associated with pores larger than $1 \mathrm{~nm}$ (Bacaoui et al., 2001). The iodine value was measured according to the procedure established by the American Society for Testing and Materials (ASTM, 1994). The mean values of data for each experiment were presented. Standard deviation was calculated from triplicate samples. Iodine Number is accepted as the most fundamental parameter used to characterize activated carbon performance.

\section{Methylene blue value}

The methylene blue value gives an indication of the adsorption capacity of an activated carbon for molecules having similar dimensions to methylene blue. It is a quick method for comparing different batches of activated carbon of the same quality. The amount of standard methylene blue decolorized (in $\mathrm{mg}$ ) by per gram of carbon (dry basis) is called methylene blue value. The higher number of methylene blue value indicates the higher adsorption capacity of activated carbon.

\section{pH value}

Activated carbon carrying inorganic and chemically active group on the surface may alter the $\mathrm{pH}$ of liquids to which it is added. A predictive standard test giving a good approximation of actual conditions has been devised. In this case, the carbon sample was extracted with boiling water and the $\mathrm{pH}$ of the extract has been defined as the $\mathrm{pH}$ value of the activated carbon.

\section{Characterization of amorphous silica}

\section{SEM-EDX}

The surface morphology of the amorphous silica was analyzed by using a scanning electron microscope (SEM) Philips, Quanta FEG 200 model equipped with an EDX spectrometer from Oxford instruments. XT microscope software was used for data acquisition and analysis. The measurement was performed at high vacuum mode with the accelerating voltage of $20 \mathrm{kV}$. Magnification range was $400 \mathrm{X}$ - 50000X and the resolution was $\geq 0.2 \mu \mathrm{m}$. 


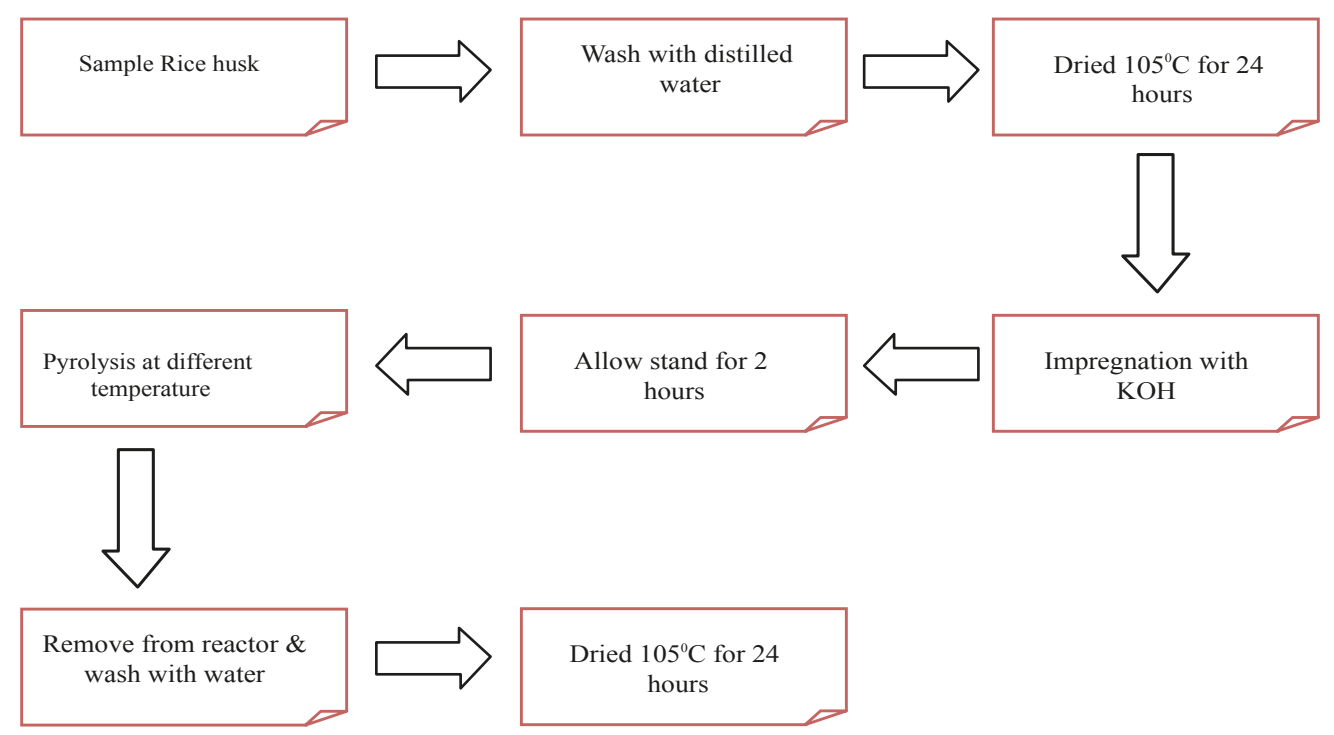

Fig. 1. Flow diagram of preparation of activated carbon by chemical activation

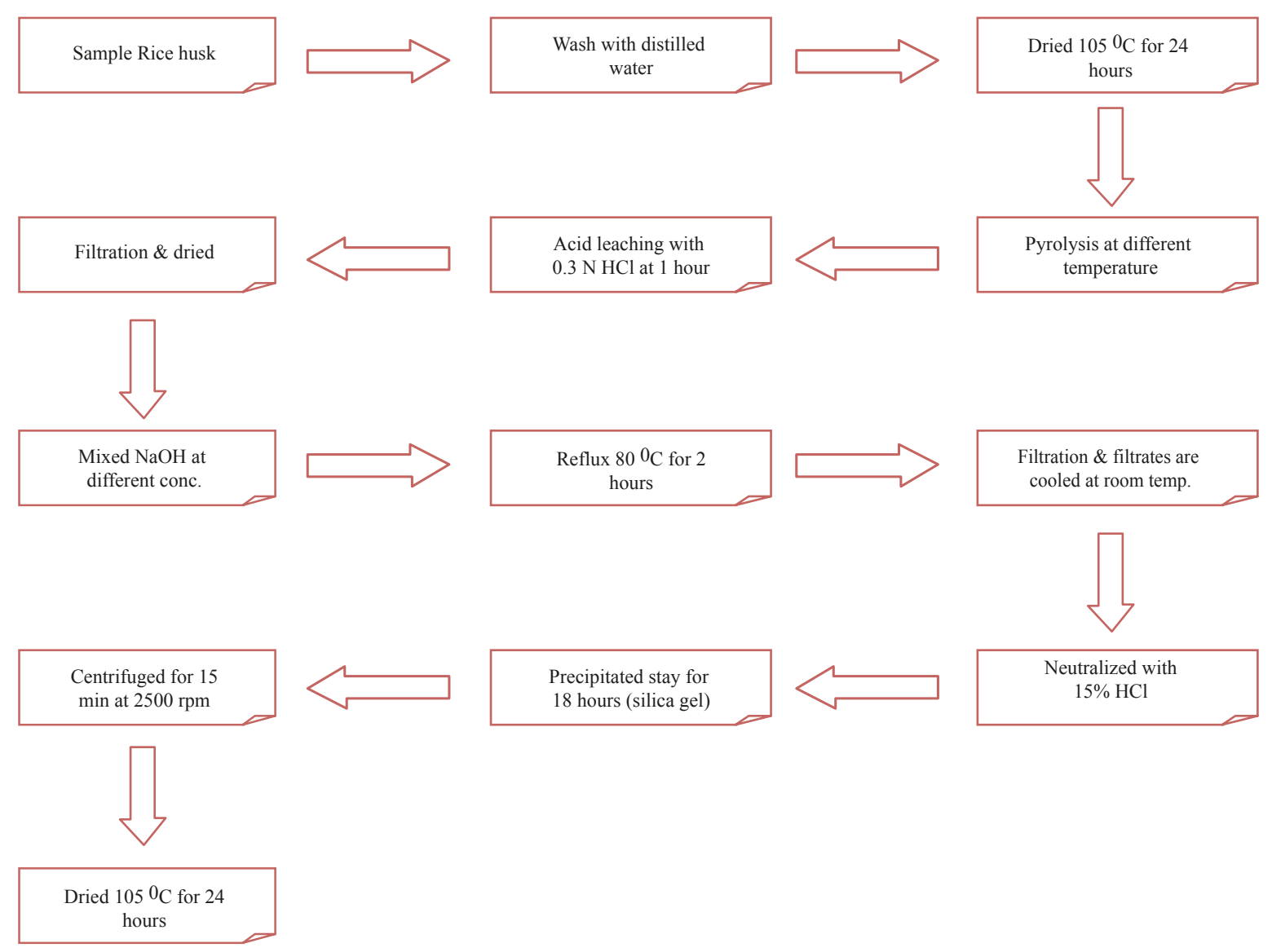

Fig. 2. Flow diagram of preparation of amorphous silica by alkali extraction method 
FTIR

FTIR analysis was made using IPrestige-21, FTIR-84005, SHIMADZU Corporation (Kyoto, Japan). Sample of $0.1 \mathrm{~g}$ was mixed with $1 \mathrm{~g}$ of $\mathrm{KBr}$ (Merk, Germany) in a mortar. Part of this mix was introduced in a cell connected to a piston of a hydraulic pump giving a compression pressure $15 \mathrm{kPa} / \mathrm{cm}^{2}$. The mix was converted to a solid disc which was placed in an oven at $105{ }^{\circ} \mathrm{C}$ for 4 hours to prevent any interference with any existing water vapor or carbon dioxide molecules. Then it was transferred to the FTIR analyzer and a corresponding chromatogram was obtained showing the wave lengths of the different functional groups in the sample which were identified by comparing these values with those in the library.

\section{Results and discussion}

Raw materials analysis dissolution of silica from rice husk into sodium silicate solution as a result the carbon yield has decreased (Fig. 3).

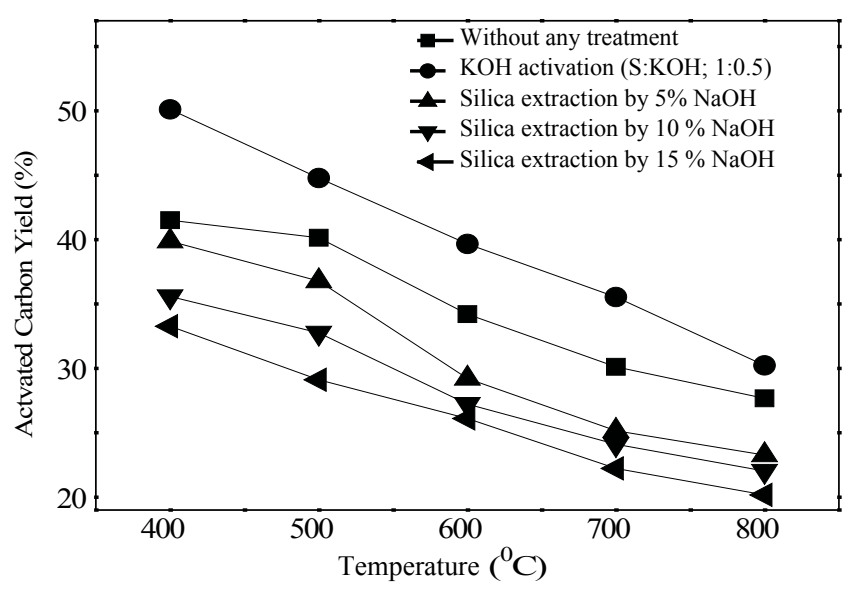

Fig. 3. Activated carbon yield with pyrolysis temperature (for 2 h)

Table I. Proximate and ultimate analysis results of collected rice husk

\begin{tabular}{cccc}
\hline Ultimate $(\mathrm{wt} \%$, dry and ash free basis) & \multicolumn{2}{c}{ Proximate $(\mathrm{wt} \%$, as received) } \\
\hline Carbon & 37.6 & Moisture & 11.2 \\
Nitrogen & 0.4 & Volatile matter & 51.9 \\
Hydrogen & 4.7 & Fixed carbon & 14.4 \\
Oxygen & 31.5 & Ash & 22.3 \\
Sulfur & 0.0 & & \\
\hline
\end{tabular}

Proximate and ultimate analysis results of collected rice husk sample have shown in Table-I. The ash and fixed carbon of the analyzed char is in favor of Activated Carbon and Amorphous Silica production. The content of each of them depends on rice variety, soil chemistry, climatic conditions, and even the geographic localization of the culture. In rice husk the fixed carbon varies from 12 to 18 and ash content varies from 17 to 22 (Iyer et al., 1997)

Effect of $\mathrm{KOH}$ activation and silica extraction by alkali on the AC yield

The Activated carbon was produced at different temperature in view to optimize the process. The mass decreased during activation was called activation burn-off and this varied with varying activation temperature. These yields of activated carbon at different temperature are summarized in Fig. 3. The yield of activated carbon decreased with increasing temperature due to the increase of the activation burn-off. The carbon yield of alkali extraction method was strongly depends on the amount of $\mathrm{NaOH}$ used. $\mathrm{NaOH}$ increase the

\section{$I_{2}$ value and $M B$ adsorption capacity of activated carbon}

The activation temperature is a very influential parameter on the pore structure of activated carbon, which determines the adsorption capacity (Hu and Vansant, 1995). The variation in iodine values of $\mathrm{AC}$ was investigated as a function of activation temperature. Fig. 4. shows there are no linear relationship between activation temperature and iodine value. This may due to increase micro pores with increasing activation temperatures (Assadullah et al., 2007). The pore size increase up to $700{ }^{\circ} \mathrm{C}$ then the pore will become thinner and at a time breakdown occurred and the number of pores was reduced. As a result the surface area and iodine number decreased at high temperatures. Thus calculated the optimum iodine value was at $700{ }^{\circ} \mathrm{C}$. Methylene blue adsorption capacity also increased with increasing of activation temperature until $700{ }^{\circ} \mathrm{C}$ (Fig. 5). This may due to increase the surface area up to $700{ }^{\circ} \mathrm{C}$. After that the surface area decreased due to closed of porosity. Another same result has explained by Gyu Hwan Oh and Chong Rae Park, 2002. 


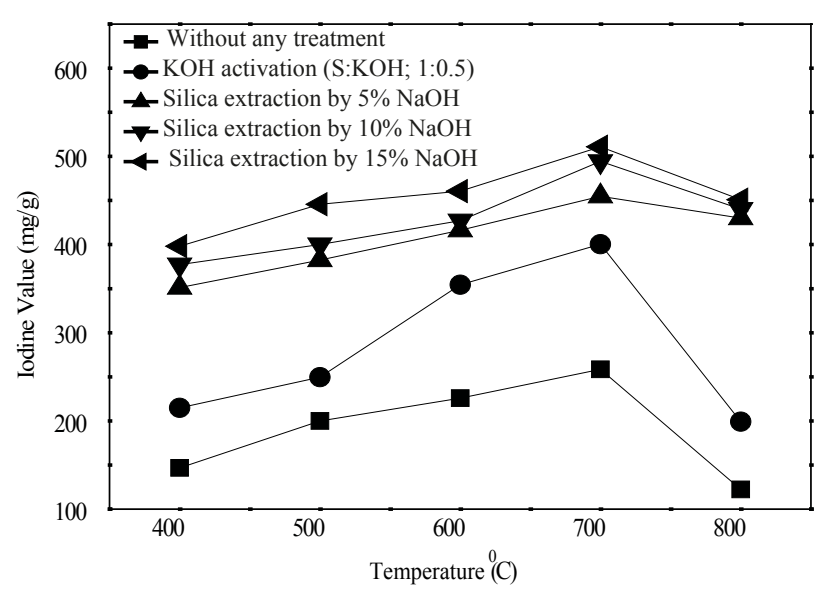

Fig. 4. Iodine value with pyrolysis temperature (for 2 h)

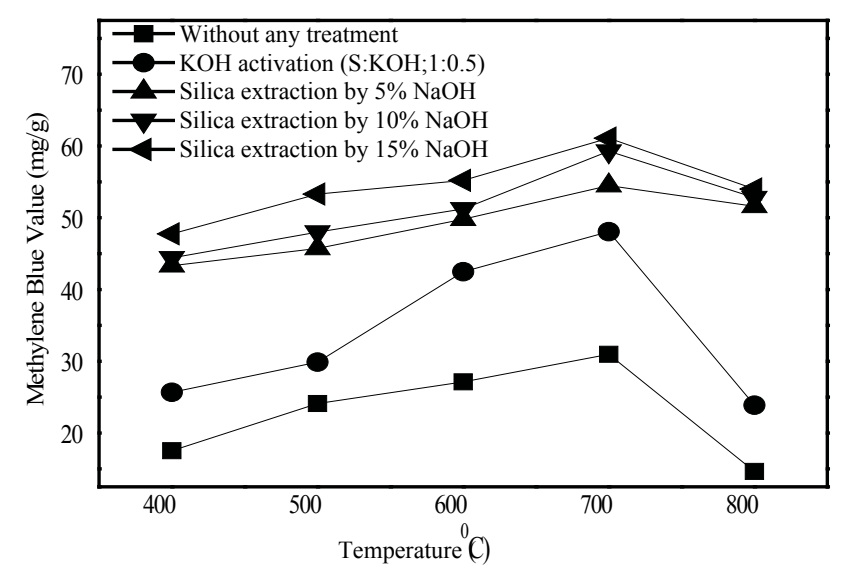

Fig. 5. Methylene blue value with pyrolysis temperature (for 2 h)

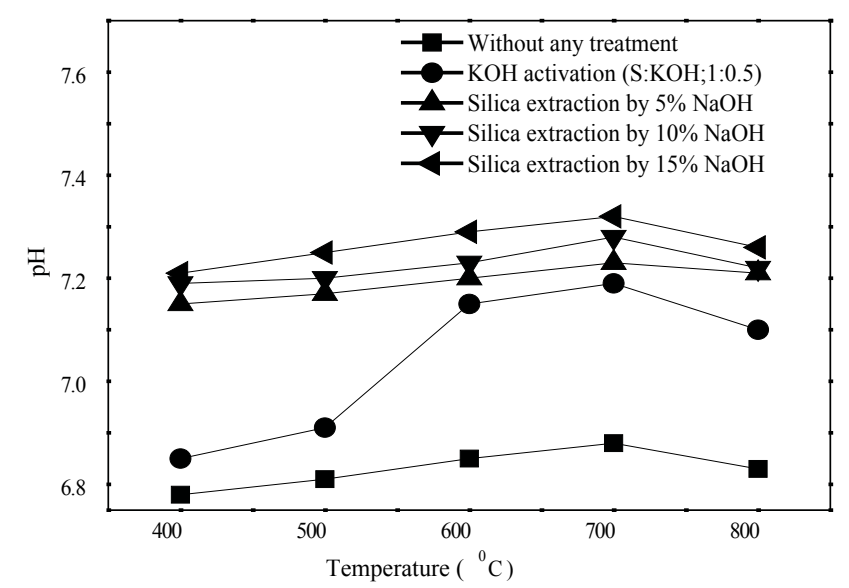

Fig. 6. pH value with pyrolysis temperature (for 2 h)

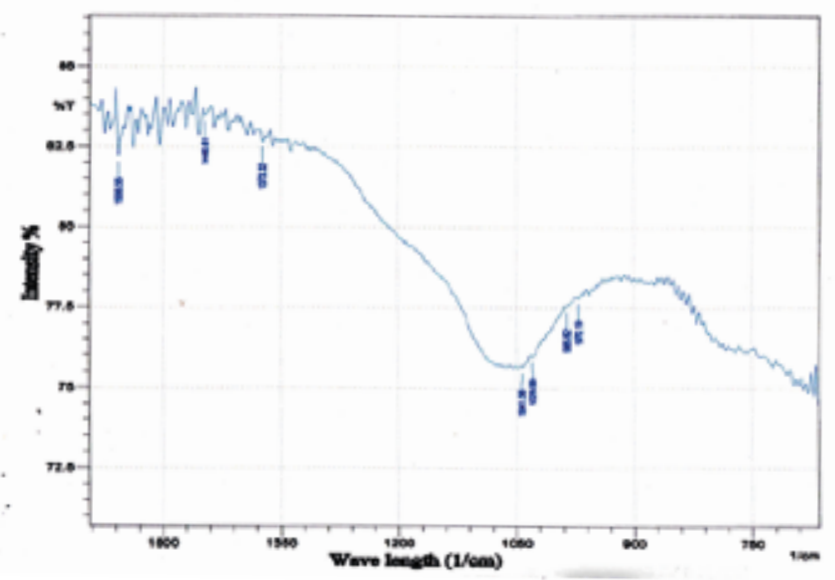

Fig. 7. FTIR spectra of activated carbon

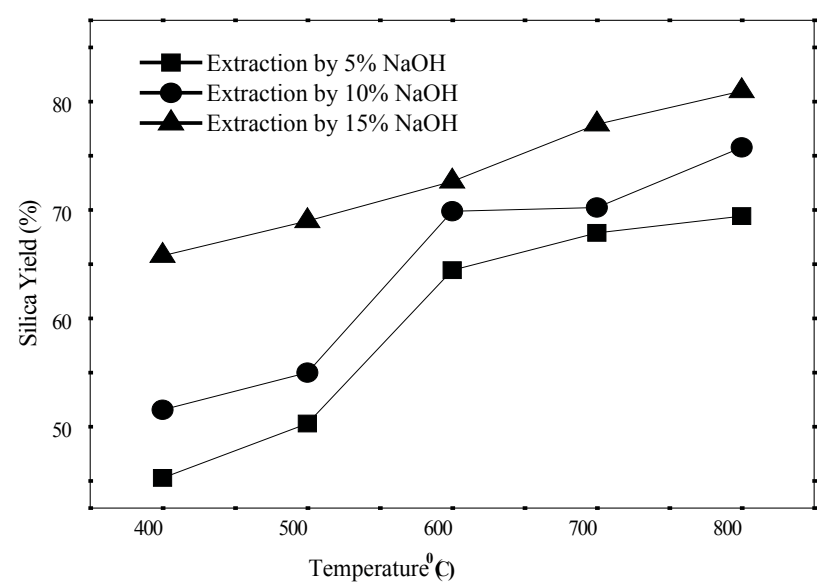

Fig. 8. Effect of $\mathrm{NaOH}$ and pyrolysis temperature on silica yield

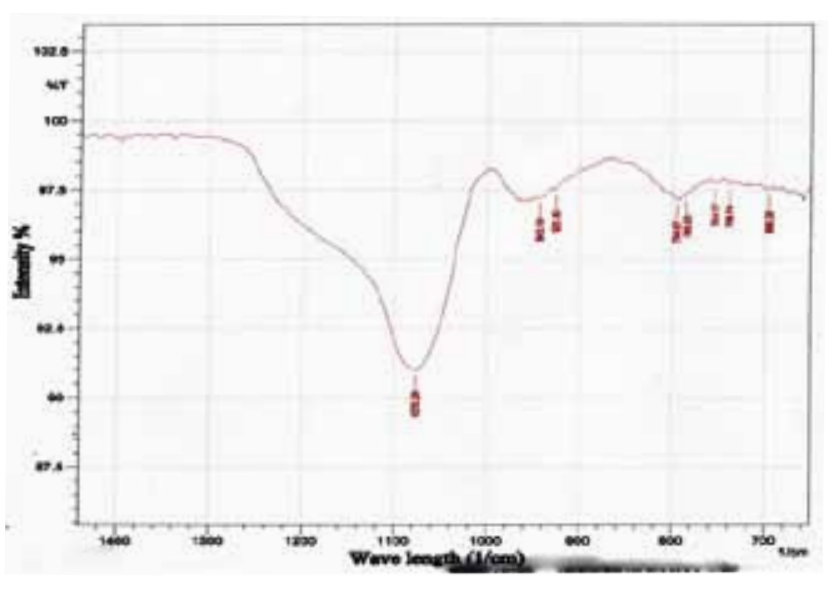

Fig. 9. FTIR spectra of amorphous silica 

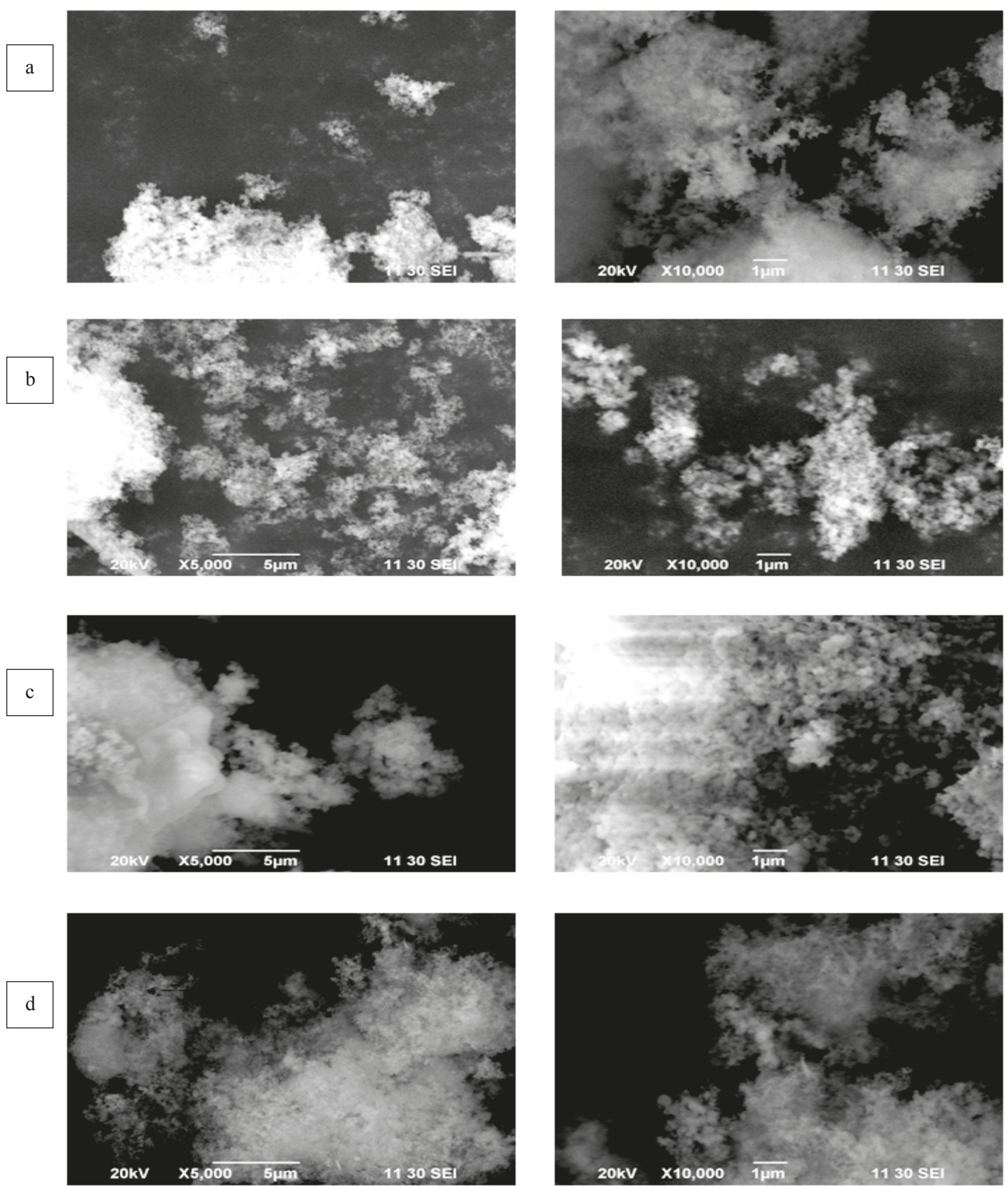

Fig. 10. SEM image of silica at different pyrolysis temperature (a) $400{ }^{\circ} \mathrm{C}$ (b) $500{ }^{\circ} \mathrm{C}$ (c) $600{ }^{\circ} \mathrm{C}$ (d) $700{ }^{\circ} \mathrm{C}$ 
Considering the dimension of methylene blue molecule is greater than that of iodine. That's why at a specific temperature the iodine value is greater than methylene blue value (Guo Y et al., 2000). Si-O bonds are liberated from the long polymeric chains ( $\mathrm{Si}-\mathrm{O}-\mathrm{C} / \mathrm{Si}-\mathrm{O}-\mathrm{Si})$ at elevated temperatures (Gorthy and Pudukottah 1999). As a result the surface of carbon may be increased due to liberated $\mathrm{Si}-\mathrm{O}$ bonds. When the pyrolysis temperatures were increased over $700{ }^{0} \mathrm{C}$ more $\mathrm{Si}-\mathrm{O}$ was liberated but it may cause the destructive effect to the pores which reduced the surface area. This $\mathrm{SiO}_{2}$ was removed by alkali extraction with three different concentration of $\mathrm{NaOH}$. That's why the residual carbon had higher surface area then other (Fig. 4 and Fig. 5).

\section{Effect of $\mathrm{pH}$ value}

$\mathrm{pH}$ of activated carbon can be defined as the $\mathrm{pH}$ of a suspension of carbon in distilled water. Activation process increased the surface area and porosity as well as the surface basicity of activated carbon. It is due to presence of oxygen molecule in the surface. That's why larger quantities of methylene blue were adsorbed at higher $\mathrm{pH}$. The adsorption capacity will increase with increasing $\mathrm{pH}$ value which also increases up to $700^{\circ} \mathrm{C}$ (Fig. 6). After that the $\mathrm{pH}$ will decrease. The same results also have seen by Santhi and Manomani, (2009).

\section{Functional Group Analysis of AC}

The FTIR spectra were recorded for qualitative characterization of surface functional groups of the activated carbon. Fig. 7. shows that the alkyl aromatic carbon structure (C-H stretching bands at 900-700 $\mathrm{cm}^{-1}$ ) with numerous oxygen containing functional groups: C-O-(C) $\left(1375 \mathrm{~cm}^{-1}\right)$ and C-O- $(\mathrm{H})\left(1050 \mathrm{~cm}^{-1}\right)$. The band of the spectra $\left(1600 \mathrm{~cm}^{-1}\right)$ can be due to aromatic skeletal mode (Sun and Tomkinson, 2001; Bouwman and Freriks, 1980).

\section{Effect of $\mathrm{NaOH}$ and pyrolysis temperature on silica yield}

Silica yield increased with the increasing concentration of $\mathrm{NaOH}$ and also with the increasing temperature of pyrolysis. Fig. 8. shows the effect of $\mathrm{NaOH}$ and pyrolysis temperature on silica yield. Because $\mathrm{Si}-\mathrm{O}$ parts were liberated from the long polymeric chains ( $\mathrm{Si}-\mathrm{O}-\mathrm{C} / \mathrm{Si}-\mathrm{O}-\mathrm{Si}$ ) with temperature (Gorthy and Pudukottah 1999). As a result the yield of silica may increase due to liberated $\mathrm{Si}-\mathrm{O}$ bonds. This $\mathrm{SiO}_{2}$ is removed by alkali extraction.

$$
\begin{gathered}
\mathrm{SiO}_{2}+2 \mathrm{NaOH}=\mathrm{Na}_{2} \mathrm{SiO}_{3}+\mathrm{H}_{2} \mathrm{O} \\
\mathrm{Na}_{2} \mathrm{SiO}_{3}+2 \mathrm{HCl}=2 \mathrm{NaCl}+\mathrm{SiO}_{2}+\mathrm{H}_{2} \mathrm{O}
\end{gathered}
$$

Functional Group Analysis of Silica

The major chemical groups present in the silica were identified by FTIR spectra. The IR spectra of silica can be seen in Fig. 9. It showed very strong bands at the wave number $1076.28 \mathrm{~cm}^{-1}$ due to asymmetric stretching of Si-O-Si group. The IR band for silanol groups were showed at $943.19 \mathrm{~cm}^{-1}$. Si-O stretching for alkali silicate glasses showed at $794.67 \mathrm{~cm}^{-1}$, at $794.67 \mathrm{~cm}^{-1}$ for Si-O-Si symmetric stretching vibrations and band at $460-480 \mathrm{~cm}^{-1}$ is due to O-Si-O bending vibration.

\section{Surface morphology analysis of silica}

The morphological features of the amorphous silica observed by scanning electron microscopy (SEM) at different temperature are shown in Fig. 10. From these figures it is clearly seen that amorphous silica has porous and multifaceted particle shape and size. The morphology seen in figure can be attributed to the burning out of the organic component in the rice husk during combustion. The primary particles size showed a tendency to from bigger particles (aggregates). The hydrated silica subsequently polymerizes to form a skeletal silica network which may explain in the SEM micrograph in Fig. 10.

\section{Conclusion}

Experiments were conducted to investigate the potential of rice husk as a raw material for the production of activated carbon and amorphous silica. The optimum temperature for production of activated carbon of highest activity was obtained at $700{ }^{\circ} \mathrm{C}$ with $\mathrm{KOH}$ impregnated rice husk and $\mathrm{NaOH}$ extracted char. The result of silica yield (\%) increase with increasing temperature and concentration of $\mathrm{NaOH}$ for extraction. The SEM image show that amorphous silica has porous and multifaceted particle shape and size \& most of organic component is burning out during combustion. Experimental result show that it was feasible to produce activated carbon and amorphous silica from rice husk by the conventional carbonization followed by alkali extraction and by chemical activation method using potassium hydroxide as activating agent.

\section{References}

Alvarez J, Lopez G, Amutio M, Bilbao J, and Olazar M (2015), Physical Activation of Rice Husk Pyrolysis Char for the Production of High Surface Area Activated Carbons, Ind. Eng. Chem. Res. 54 (29): pp $7241-7250$

ASTM (1994), American Society of Testing Materials, Philadelphia, D3173-D3175, D4607.

Asadullah M, Rahman MA, Matin MA and Sultan MB (2007), Adsorption studies on Activated Carbon derived from steam activation of Jute stick char, $J$. Surface Technol. 23(1-2): 73-80.

Bacaoui A, Yaacoubi A, Dahbi A, Bennouna C, Luu RPT, Maldonado-Hodar FJ, Rivera-Utrilla $\mathrm{J}$ and 
Moreno-Castilla C (2001), Optimization of conditions for the preparation of activated carbons from olive-waste cakes, Carbon 39(3): 425-432.

Bining AS and Jenkins BM (1992), Thermo chemical reaction kinetics for rice straw from an approximate integral technique, Am. Soc. Agric. Eng. ASAE paper No. 92-6029, St. Joseph, MI.

Bouwman R and Freriks ILC (1980), Low-temperature oxidation of a bituminous coal. Infrared spectroscopic study of samples from a coal pile, Fuel 59(5): 315-322.

Chen JM and Chang FW (1991), The chlorination kinetics of Rice Husk, Indian Eng. Chem. Res. 30: 2241-2247.

Ghosh TB, Nandi KC, Acharya HN and Mukherjee D (1991), XPS Studies of Magnesium Silicide Obtained from Rice Husk, Mater. Lett. 11: 6-9.

Gorthy P and Pudukottah MG (1999), Production of Silicon Carbide from Rice Husks, J. Am. Cer. Soc. 82(6): 1393-1400.

Guo Y, Yu K, Wang Z and Xu H (2000), Effects of activation conditions on preparation of porous carbon from rice husk, Carbon 41: 1645-1648.

Guo YP, Yang SF, Yu KF, Zhao JZ, Wang ZC and Xu HD (2002), The preparation and mechanism studies of rice husk based porous carbon, Mater Chem Phys 74: $320-323$.

Gyu Hwan Oh and Chong Rae Park (2002), Preparation and cheracteristics of rice-strow-based porous carbons with high adsorption capacity, Fuel 81: 327-336.

Houston DF (1972), Rice Hull: Rice Chemistry and Technology, American Association of Cereal Chemists Inc., St. Paul, MN, pp 301-352.

$\mathrm{Hu} \mathrm{Z}$ and Vansant EF (1995), A new composite adsorbent produced by chemical activation of elutrilithe with zinc chloride, J. Colloid Interface Sci. 176(2): 422-431.

Iyer PVR, RAO TR, Grover, PD, Singh NP (1997), Biomass Thermo-Chemical Characterisation, $2^{\text {nd }}$ Ed. p 42.

Kalderis D, Bethanis S, Paraskeva P and Diamadopoulos E (2008), Production of activated carbon from bagasse and rice husk by single stage chemical activation method at low retention times, Bioresour Technol 99(15): 6809-6816.

Liu Y, Guo Y, Gao W, Wang Z, Ma Y and Wang Z (2012), Simultaneous preparation of silica and activated carbon from rice husk ash, J. Clean. Prod. 32: 204-209.

Liu Y, Guo Y, Zhu Y, An D, Gao W, Wang Z, Ma Y and Wang Z (2011), A sustainable route for the preparation of activated carbon and silica from rice husk ash, $J$. Hazard. Mater. 186(2-3): 1314-1319.

Martin MJ, Artola A, Balaguer MD and Rigola M (2003), Activated carbons developed from surplus sewage sludge for the removal of dyes from dilute aqueous solutions, Chem. Eng. J. 94(3): 231-239.

Nandi KC, Biswas AK and Acharya HN (1991), Density-of-states determination in hydrogenated amorphous silicon obtained from Rice Husk, Mater. Lett. 12: 171-174.

Patel M, Karera A and Prasanna P (1987), Effect of Thermal and Chemical Treatment On Carbon and Silica Contents in Rice Husk, J. Mater. Sci. 22: 2457-2464.

Real C, Alcala MD and Criado JM (1996), Preparation of silica from rice husks, J. Am. Chem. Soc. 79: 2012-2016.

Santhi T and Manonmani S (2009), Removal of methylene blue from aqueous solution by bioadsorption onto Ricinus communis epicarp activated carbon, Chem. Eng. Res. Bulletin 13: 1-5.

Shigetaka W, Weerasak M and Zhemchai H (2005), Survey of the Research on the utilization of Rice Husk and Rice Husk Silica, Proc. $1^{\text {st }}$ workshop on the utilization of Rice Husk and Rice Husk Silica, Bangkok, Thailand, 6-14.

Sun RC and Tomkinson J (2001), Fractional separation and physico-chemical analysis of lignins from the black liquor of oil palm trunk fibre pulping, Sep. Purif. Technol. 24(3): 529-539.

Van K L and Thi T T L (2014), Activated carbon derived from rice husk by $\mathrm{NaOH}$ activation and its application in supercapacitor, Material International 24(3): 191-198

Yamaguchi T, Sekiguchi T, Toyoshima H, Kohira E, Shikano S and Hokkirigawa K (2006), Friction and wear properties of new hard porous carbon materials made from Rice Chaff, Proc. $3^{\text {rd }}$ Asia Int. Conf. Trib., 379-380.

Received: 1 June 2015; Revised: 22 September 2015;

Accepted: 19 October 2015. 